\title{
Uma proposta metodológica para análise política e institucional de consórcios públicos como espaços de gestão compartilhada de políticas
}

\author{
Alexsandro Sousa Brito \\ Universidade Federal do Maranhão
}

Os consórcios públicos são conhecidos pela capacidade de arregimentar entidades públicas e privadas em torno de um problema comum, que dificilmente lograria solução pela ação isolada de um único ente, bem como são conhecidos pela possibilidade de produção de políticas compartilhadas. Contudo, a constituição desses arranjos, nesse sentido, é problemática, dada a complexidade da promoção de ações colaborativas e dados os constrangimentos no processamento institucional de espaços efetivamente participativos e democráticos. Nesse sentido, este artigo sugere parâmetros para análise institucional e política de consórcios públicos, a partir dos problemas mais frequentes encontrados nas evidências empíricas dessas experiências em nível nacional e internacional; partindo, também, das contribuições teóricas sobre a construção da democracia representativa. 0 objetivo fundamental é propor um quadro para análise das experiências de consorciamento, a fim de entender os fatores que obstam formas de gestão compartilhada entre os municípios e outros entes públicos (cooperação intergovernamental) e que dificultam a estruturação dos consórcios como espaços mais públicos e democráticos (democracia participativa).

Palavras chave: consórcio público, relações intergovernamentais, democracia 


\section{Una propuesta metodológica para el análisis político e institucional de consorcios públicos como espacios de gestión compartida de políticas}

Los consorcios públicos son conocidos por la capacidad de arregimentar entidades públicas y privadas en torno a un problema común, que difícilmente lograría solución por la acción aislada de un solo ente y, también, por la posibilidad de producción de políticas compartidas. Sin embargo, la constitución de esos arreglos, en ese sentido, es problemática, dada la complejidad de la promoción de acciones colaborativas y dados los constreñimientos en el procesamiento institucional de espacios efectivamente participativos y democráticos. En este sentido, este artículo sugiere parámetros para el análisis institucional y político de consorcios públicos, a partir de los problemas más frecuentes encontrados en las evidencias empíricas de esas experiencias a nivel nacional e internacional; partiendo de las contribuciones teóricas sobre la construcción de la democracia representativa. El objetivo fundamental es proponer un marco para el análisis de las experiencias de consorciamiento, a fin de entender los factores que obstaculizan formas de gestión compartida entre los municipios y otros entes públicos (cooperación intergubernamental) y que dificultan la estructuración de los consorcios como espacios más públicos y democráticos (democracia participativa).

Palabras clave: consorcio público, relaciones intergubernamentales, democracia

\section{A methodological proposal for political and institutional analysis of public consortia as spaces for shared policy management}

Public consortium is known for their ability to bring together public and private entities around a common problem that would be difficult to solve by the single action of a single entity and also by the possibility of producing shared policies. However, the constitution of these arrangements in this sense is problematic given the complexity of promoting collaborative actions and given the constraints on the institutional processing of effectively participative and democratic spaces. In this sense, this article suggests parameters for institutional and political analysis of public consortia, based on the most frequent problems found in the empirical evidence of these experiences at national and international level; starting from the theoretical contributions on the construction of representative democracy. The main objective is to propose a framework for analyzing consortium experiences in order to understand the factors that obstruct forms of shared management between municipalities and other public entities (intergovernmental cooperation) and that make it difficult to structure consortia as more public and democratic spaces (participatory democracy).

Keywords: public consortium, intergovernmental relations, democracy 


\section{Introdução}

Os consórcios públicos, em especial os intermunicipais, configuram-se como uma das várias formas possíveis de associativismo intermunicipal. Em grande parte, são decorrentes de demandas históricas de descentralização, desenvolvimento democrático e participação cidadã e emergem, com maior força, a partir da década de 1990, sobretudo quando das severas crises financeiras e sociais decorrentes do paradigma liberalizante que buscava, entre outras coisas, reduzir o tamanho da administração central, eliminar o déficit e atribuir ao mercado um papel protagonista.

Há muitas definições de consórcios públicos. Contudo, o que há de comum, em todas elas, é que os consórcios consistem em associações originadas de algum tipo de interesse mútuo e voltadas para resolver algum problema comum dos entes consorciados. Neste artigo, preferimos definir os consórcios públicos intermunicipais como arranjos institucionais de cooperação voluntária, de existência determinada ou perene, constituídos para produção específica de ações e soluções que efetivamente as entidades municipais seriam incapazes de realizar sozinhas.

Evidentemente, como já apontado em Olson (1999, 1982), a existência de problemas comuns não é uma condição suficiente para promover a colaboração, esta depende de outros aspectos, como a estrutura de incentivos, o grau de homogeneidade dos atores, o desenho institucional (Fung, 2006, 2004), entre outros. Além disso, como também ressalvado por Stoker (2003), o interesse mútuo não é bastante para amenizar as tensões nas relações intergovernamentais. Logo, portanto, a cooperação, mesmo na existência de interesses mútuos em função de problemas comuns, não é espontânea. Nesse sentido, a máxima posta por Olson (1982, p. 29) de que a ação coletiva é problemática e seus resultados incertos ainda parece bastante válida.

De todo modo, a constituição dos arranjos consorciais, mesmo problemática, pode representar um avanço em duas principais dimensões: a da cooperação intergovernamental, no que diz respeito à gestão compartilhada de responsabilidades públicas (TREVAS, 2007) ou à coordenação e cooperação federativas (ABRUCIO; SANO; SYDow, 2010, p. 12); e a da democracia participativa, considerando que possam diminuir a distância entre a sociedade e o Estado nos processos deliberativos, o que representaria um alargamento do Estado democrático (BRITO, 2017).

A partir das duas dimensões supracitadas, a proposta deste artigo é apresentar um conjunto de parâmetros para análise política e institucional da implementação de consórcios públicos. O objetivo é propor um quadro para análise das experiências de consorciamento, a fim de entender os fatores que obstam formas 
de gestão compartilhada entre os municípios e outros entes públicos (cooperação intergovernamental) e que dificultam a estruturação dos consórcios como espaços mais públicos e democráticos (democracia participativa)

Para embasar a proposta, partiu-se de uma revisão de literatura que registra algumas experiências nacionais e internacionais de consorciamento, em que se apresentam algumas evidências dos principais gargalos que embaraçam a gestão compartilhada e comprometem a construção de um espaço participativo e democrático pelos consórcios.

Em seguida, recuperaram-se, minimamente, alguns elementos teóricos, no tocante à participação e à constituição do problema público, que ajudam a compreender a complexidade do espaço da produção das políticas, e que precisam ser considerados no entendimento das deliberações que são feitas pelos consórcios públicos. Como lembrado por Castellano (2007), a construção da relação entre o poder público e a sociedade depende, além do capital social e do processo de formação institucional, da forma como são implementadas as políticas públicas.

Logo após, apresentam-se os parâmetros para análise de consórcios públicos, que tentam capturar elementos cruciais no tocante à institucionalidade dos consórcios, à construção dos problemas comuns, à governança, à estrutura financeira e à participação.

\section{Problemas, limites e obstáculos de algumas experiências internacionais e nacionais de consorciamento}

Analisando as experiências de consorciamento europeu, especificamente da Alemanha, França, Itália, Finlândia, Bélgica, Espanha, Reino Unido e Holanda, Hulst e Monfort (2007) observam duas questões políticas importantes: a) primeiro, quanto à capacidade de decisão: algumas experiências de consorciamento acabam transferindo o poder de decisão a órgãos regionais legalmente estabelecidos, enquanto outras a alguma outra autoridade estabelecida em comum acordo pelos entes consorciados; b) segundo, quanto à questão da representação política e à responsabilização: os autores apontam que há dificuldades em se estabelecerem eleições diretas para os representantes junto aos consórcios constituídos, sobretudo pelo receio dos governos locais de se estabelecerem órgãos suprarregionais superiores aos governos locais, implicando numa indefinição na representação política junto aos consórcios.

De acordo com Jouve e Lefevre (2007), os consórcios são exemplos das transformações institucionais que têm mudado as estruturas internas dos Estados europeus, transferindo maiores responsabilidades políticas e administrativas às 
comunidades locais e regionais. Contudo, ressalta que essas mudanças não têm sido neutras e, em grande parte, as reformas que perseguem a consolidação da democracia local o fazem num contexto de reforço da hegemonia neoliberal.

Segundo esses autores, as políticas buscam soluções adaptadas aos efeitos locais e, por isso, o Estado não mais determina seu território inteiro baseado em uma lógica institucional única, mas proporciona aos atores metropolitanos uma capacidade maior de se organizar e de construir seu próprio marco de trabalho para interação, mediante o estabelecimento de estruturas governamentais que se unem aos atores públicos e aos representantes da sociedade civil.

Isso tem sido resultado da produção de reformas com o objetivo de acercar ao poder local o cidadão, em particular, de proporcionar acesso à esfera de tomada de decisões, através do processo de descentralização. Porém, a descentralização tem sido acusada de não ser tão democrática por manter e inclusive ampliar a distância entre o poder político e os cidadãos (JOUVE; LEFEVRE, 2007).

No caso espanhol, Gutierrez, Fernandez e Nevado (2007) identificam os consórcios como uma forma de cooperação com características inovadoras e flexíveis para fazer frente à gestão de serviços públicos tanto de alcance intermunicipal como provincial, principalmente pela possibilidade de aberturas a novos atores sociais.

Contudo, isso não sugere ausência de obstáculo na promoção de ações públicas. Um caso interessante é destacado por Collantes (2006) ao analisar o caso de um consórcio transacional, realizado por municípios da região de Bidasoa (Espanha) com um município francês, Consórcio de Bidasoa-Txingudi. O autor observa que o consórcio intermunicipal internacional foi formado em função do contexto internacional, em especial, no período mais recente da integração da Espanha à comunidade europeia.

Essa integração teve como consequência o desaparecimento das atividades aduaneiras (dada a liberalização das transações econômicas e a criação de um mercado comum) nos municípios circunscritos na área do Rio Bidasoa, os municípios de Irun, Hondarrabia (lado espanhol) e Hendaia (lado francês). Essas atividades constituíam-se no motor principal da atividade econômica desses municípios, aliás, em todas aquelas localidades e territórios que se haviam desenvolvido em torno das atividades alfandegárias, característica de todas as regiões fronteiriças desse território.

Segundo o autor, o consórcio passa a ser um elemento-chave para o funcionamento e planejamento da conurbação de Bidasoa, através de ações em vários campos, como comunicação, urbanismo e infraestrutura; turismo, desporto, cultura e informação cidadã. Mas há também, segundo o autor, obstáculos, como a necessidade de superar a mera colaboração em determinadas ações; a necessidade 
de se passar mais efetivamente para planejar o desenvolvimento da região; o obstáculo jurídico-administrativo, dada a configuração de administração pública extraordinária, formada por municípios de estados e legislações diferentes; e a grande dependência e sua estreita vinculação administrativa com a Agência de Desenvolvimento Adebisa (Agencia de Desarollo del Bidasoa S/A), o que acaba influenciando na sua capacidade de coordenação e autonomia.

Além desses problemas, o autor observa, ainda, a excessiva dependência dos aportes financeiros externos e a dificuldade em atuar em campos mais complexos, como os de áreas estratégicas como desenvolvimento econômico; o consórcio acaba focando, principalmente, em atividades de desporto e ligadas à educação, e, com isso, acaba atuando, em geral, no âmbito das competências municipais, descaracterizando o propósito para o qual foi criado.

Nas experiências latinoamericanas, os casos argentino e brasileiro destacamse como os mais proeminentes (BRITO, 2017). Segundo Cravacuore (2000), as experiências do caso argentino, em geral, caracterizam-se por serem relativamente recentes, pouco frequentes e ainda sem uma representação adequada na agenda pública local.

O balanço que o autor faz, analisando algumas experiências, é de que a cooperação intermunicipal é frouxa e que as relações que se estabelecem com a unidade de gestão do consórcio (organismo extramunicipal) parece reproduzir as relações tradicionais entre municípios e governo provincial, como negociações restrita ao máximo nível político, inexistência de cooperação entre os corpos técnicos municipais participantes do consórcio e poder de decisão transferido para os níveis técnicos do organismo extramunicipal.

Essa tese também é compartilhada por Cáceres (2005) ao analisar a experiência de consorciamento em Córdoba; a autora identificou que o processo de reforma do Estado privilegiou apenas o aspecto fiscal e que questões importantes para o desenvolvimento regional e territorial ficaram de fora. Além disso, a autora também salienta que a relação entre o município e a província reproduz as mesmas relações que existem entre a nação e a província, controlando, orientando grande parte dos recursos de que dispõem os municípios, fazendo-os altamente dependente da província.

As análises feitas por Choconi (2006), sobre muitas das experiências estudadas por Cravacuore (2006, 2000) e Cáceres (2005), é ainda mais incisiva: a autora chega a afirmar que as experiências de consorciamento produtivo alçadas pelos municípios faliram porque os consórcios não executaram ações como uma jurisdição diferente do local, não se impuseram como uma entidade supralocal, muito menos formularam ou executaram políticas comuns para o território. Os 
projetos executados foram pouco significativos e de irrelevância econômica para a microrregião envolvida e para a província.

Analisando as causas fundamentais disso, a autora destaca o peso das políticas setoriais sobre qualquer outra formulação que introduza o tema regional, dado o não reconhecimento, por parte das províncias, dos consórcios como interlocutores. Além disso, a autora aponta as dificuldades decorrentes da ausência de personalidade jurídica dos consórcios, o que só veio a se reverter no final da década de 1990. Aponta, também, as dificuldades dos Executivos municipais em superar a lógica político-administrativa em que se baseava a relação isolada de cada município com o poder provincial. Essa situação contribuiu, segundo a autora, para inibir a possibilidade de articulação de estratégias associativas que fizessem valer a capacidade de lobby de cada consórcio.

Um balanço geral dos casos de consorciamento, feito em Cravacuore (2006) com mais de 70 municípios na Argentina, sintetiza alguns dos principais problemas que esses novos arranjos institucionais enfrentam hoje em dois aspectos: dificuldades políticas e de gestão.

No tocante ao primeiro aspecto, o autor aponta a associação entre política e território, que mostra como, tradicionalmente, a gestão local toma como referência os limites estritos do seu território, sem considerar que as políticas locais podem influenciar escalas jurídico-administrativas maiores, em outras palavras, o autor quer dizer que é difícil para os funcionários municipais pensar as políticas locais desde uma perspectiva regional; outra dificuldade diz respeito à existência de políticas pouco favoráveis ao associativismo intermunicipal, tanto nacionais como provinciais, o que implica que esses consórcios ou as comarcas dificilmente aparecem como interlocutores do governo provincial, que, geralmente, prefere manter vínculos diretamente com os governos locais.

Há, também, dificuldades decorrentes do que o autor chama de reprodução de padrões políticos de articulação radial, que ocorre quando um município maior exerce poder ou influência sobre municípios menores, da mesma forma que as províncias exercem seu poder assimetricamente sobre os governos locais. Esse tipo de relação leva alguns municípios a se estruturarem em torno do governo local cuja liderança política leva outros. Por último, o autor chama a atenção para a falta de apropriação da associação intermunicipal nas estratégias de desenvolvimento local. Isso parece paradoxal, mas o autor lembra que, em geral, os arranjos institucionais acabam se circunscrevendo no âmbito estatal, não abarcando a inclusão da iniciativa privada e nem das organizações da sociedade civil.

No tocante às dificuldades de gestão, o balanço feito pelo autor mostrou como dificuldades fundamentais: a falta de sustentação orçamentária dessas iniciativas, 
a dificuldade de gestão cotidiana quer seja administrativa (adequação aos procedimentos usuais) ou espacial, que se refere às excessivas distâncias entre os entes, o que dificulta a comunicação, entre outras.

O caso brasileiro talvez represente, na América Latina, o melhor exemplo de desenvolvimento e consolidação dessas experiências. Há uma farta literatura que registra as inovações nas mais distintas experiências de consorciamento ${ }^{1}$.

A pesquisa empreendida por Dallabrida e Zimermann (2009), por exemplo, analisando mais de quarenta consórcios no Rio Grade do Sul, mostrou que a constituição desses arranjos (entre meados dos anos 1980 até 2005) logrou-se num ambiente com pouca participação da União, dos estados e da sociedade civil, bem como evidenciou as grandes dificuldades na gestão de diversos consórcios, principalmente em função da ausência de instrumentos de planejamento de médio e longo prazo, o que favoreceu a inativação e extinção de alguns desses arranjos.

Uma das questões levantadas por Keinert e Rosa (2001) refere-se ao efetivo papel desempenhado por esses arranjos. No caso da saúde, no Paraná, os autores observam que ao longo dos anos os consórcios desempenharam uma função de prestadores de serviços de saúde e bem menos de gestores da saúde no plano microrregional. Situação essa decorrente, principalmente, do fato de que esses arranjos acabaram tratando da assistência (prestador de serviço), equipando-se para atender a demanda em detrimento da prevenção e organização do serviço de saúde, o que exigiria fina sintonia com a esfera estadual para gestão da saúde.

Nas considerações feitas por Leite, Gomide e Silva (2001), quanto aos modelos organizacionais dos consórcios, destacou-se que a heterogeneidade entre os municípios no tocante à realidade socioeconômica poderia constituir-se em dificuldades na implementação das ações, com uma tendência ao predomínio dos municípios de maior porte, sendo necessário planejamento e coordenação de ações microrregionais.

Das contribuições aportadas por Mantovani (2001), quanto aos obstáculos que precisam ser superados, elencamos os que consideramos os mais salientes: falta de visibilidade dos consórcios, ausência de democratização das informações e a frágil atuação do poder público na promoção de ações integradas.

Cruz et al. (2005a) apontam que as diferenças de porte e as distâncias entre os municípios podem favorecer a desarticulação e o desarranjo, ao limitar os interesses comuns. Por outro lado, o próprio acesso aos recursos, facilitado pelo

\footnotetext{
${ }^{1}$ Podemos citar, por exemplo, Keinert e Rosa (2001), Guimarães e Gomes (2001) e Cruz (2001) - na área da saúde; Teixeira (2004), Melo et al. (2002), Matovani (2001), Lahóz e Brochi (2001) - na área do meio ambiente; e Cruz et al. (2005a; 2005b) - na área de infraestrutura. Evidentemente essa literatura também registra alguns dos principais gargalos encontrados, inclusive, nas experiências tidas como as mais exitosas de cooperação horizontal.
} 
governo estadual, para dirimir problemas das localidades, pode representar uma indução exógena que motive os municípios à adesão a programas governamentais, em detrimento da articulação aos consórcios.

Alertam ainda que a existência de um plano de desenvolvimento sofisticado e estruturado não garante a efetividade das ações, sendo fundamental que o plano de ação esteja "circunscrito no âmbito de decisão e competência do consórcio, pois a saída de um parceiro estratégico pode comprometer toda a sua atuação" (CRUz et al. 2005a, p. 28).

Outros problemas que devem ser superados nas práticas de consorciamento dizem respeito à sustentabilidade financeira; ao escopo de atuação, que deve ser compatível com os de seus participantes; e ao número e localização dos participantes, que, dependendo da natureza do consórcio, podem até inviabilizá-lo.

O que percebemos ao longo da análise dessas experiências é que, em geral, os consórcios apresentam grande déficit de implementação, no que diz respeito à capacidade de implementar formas de gestão compartilhada de políticas. Alguns aspectos parecem-nos nodais: a problemática do processo de deliberação, a concertação política, os mecanismos de negociação, a capacidade de debelar ou atenuar conflitos, a densidade institucional do próprio arranjo, a capacidade financeira, entre outros. Em nosso entendimento, a análise desses aspectos é fundamental para iluminar grande parte dos problemas que cercam o processo de construção dos consórcios enquanto espaços para produção compartilhada de políticas públicas.

A despeito dos problemas que embaraçam a colaboração nos arranjos consorciais, para alguns, como Fonseca (2013), os consórcios têm a capacidade de institucionalizar estratégias de resolução de problemas regionais, por meio de arranjos públicos e da concertação e mobilização de distintos atores, embora se saiba que essa mobilização é problemática. Em tese, isso sinalizaria para a possibilidade, posta pelos consórcios públicos, de ultrapassagem dos obstáculos político-administrativos impostos pela Federação brasileira; e para a redução das desigualdades e garantia da diversidade, a partir dos mecanismos de cooperação e coordenação implementados por esses arranjos, pela capacidade, que podem ter, de diminuir a necessidade de serviços públicos fundamentais e de implementar políticas quasi redistributiva (LACZYNSKI; ABRUCIO, 2013).

A questão que se coloca, portanto, é como analisar o processo de implementação de consórcios públicos, considerando tanto o desenho institucional como os aspectos políticos que podem obstruir ou fazer avançar a produção compartilhada de políticas. Nesse aspecto, considerando os problemas 
suscitados nas experiências de consorciamento, rapidamente descritas acima, algumas questões tornam-se extremamente relevantes para entender o processo de implementação dos consórcios.

Uma primeira questão é entender como o problema público, que arregimenta, em tese, os municípios signatários, é construído. Será que a formulação do problema parte de uma identidade comum aos territórios, ou é induzida por agências ou atores relevantes, ou ainda é produto do intercâmbio cultural dos sujeitos? Esse aspecto nos parece fundamental em função de ser ele o fator que definirá o papel do consórcio.

A questão da definição do problema comum pode ser melhor visualizada a partir dos problemas enfrentados por algumas experiências (previamente citadas) que não conseguiam se diferenciar de uma jurisdição local, não conseguiam formular políticas comuns, atuando meramente como prestadores pontuais de serviços públicos, e que, muitas vezes, incorreram em sobreposição de competências com agências locais sem conseguir afetar a orientação setorial das políticas públicas. Isso sugere que muitas experiências acabaram se constituindo sem uma definição clara de um problema de fato comum, ou que não conseguiram estabelecer articulações com instâncias relevantes de promoção de políticas. Nesse cenário, os consórcios podem não aparecer como grandes interlocutores, pois não há um problema comum que estimule a ação conjunta.

Uma segunda questão diz respeito à institucionalidade do consórcio. Como visto, muitos problemas decorrem da vinculação do consórcio com outras agências, anulando, em certo sentido, sua autonomia e representatividade; outros decorrem da dificuldade de articulação vertical e horizontal, ou mesmo da desarticulação em função da indução exógena (direcionamento das políticas em função dos recursos federais ou estaduais). Nesse sentido, é importante apreender em que medida os consórcios possuem envergadura institucional suficiente para conduzir ações públicas de maneira autônoma.

Outro aspecto que merece atenção é o que diz respeito à democracia. Muitas das experiências argentinas e também europeias não conseguiram lograr estruturas mais democráticas e participativas. Muitas dessas experiências, como vimos, também podem se inserir numa dinâmica de competição entre territórios e regiões, obedecendo a uma lógica neoliberal que ameaça a concertação de uma estrutura democrática. Evidentemente a ameaça não se faz apenas por uma estratégia de competição, mas pelo modo de gestão insular, pela ausência de articulação e coordenação interinstitucional, pelo reduzido espaço de participação e, também, pela reprodução das formas e relações organizacionais e institucionais tradicionais. Nesse sentido, é importante considerar se a estruturação dos consórcios se pauta 
no processamento institucional de estratégias e mecanismos de participação e de instrumentos de governança democrática.

\section{Consórcios públicos e produção de políticas democrático-participativas: breves considerações sobre a participação e a definição do problema público}

Considerar a análise do processo de implementação de consórcios públicos a partir da efetividade de formas de gestão compartilhada passa, ainda, pela consideração de estratégias democrático-participativas (DAGNINO; OLVERA; PANFICHI, 2006; SANTOS; AVRITZER, 2002) na formulação, execução e gestão das ações públicas fomentadas pelos próprios consórcios.

A participação, como já apontado por Pateman (1992), além de cumprir um papel pedagógico e de controle, é o elemento que enraíza as relações de cooperação, que se estabelecem pelo ato da vontade; em outras palavras, é a substancia que fundamenta e origina estruturas organizacionais colaborativas ou de cooperação. Logo, uma política de consorciamento verdadeiramente democrática deverá ser, essencialmente, participativa. Assim os consórcios públicos só podem se estabelecer como uma forma de gestão democrática, se forem, por definição, participativos.

A autora observa que a participação ${ }^{2}$ está associada à sensação de pertencimento à comunidade, que decorre do fato de a participação cumprir algumas funções importantes. A primeira diz respeito à função educativa, que consiste na construção de um sistema individual e socialmente responsável, em que cada um aprende que é preciso considerar problemas bem mais abrangentes do que os seus próprios e imediatos interesses privados, caso queira a cooperação dos outros, apontando, assim, que o interesse público e privado se encontram ligados. Nessa acepção, o aprendizado da distinção entre os próprios impulsos e desejos implica no aprendizado daquilo que é ser cidadão. Nesse sentido o processo participativo também capacita; quanto mais o cidadão participa, mas ele se torna capacitado para fazê-lo.

A participação também teria a função de controle, no sentido de garantir a liberdade, entendida como obediência à lei que alguém prescreve a si mesmo e decorrente do fato de que a sensação de liberdade efetiva aumenta à medida que aumenta, também, a participação na tomada de decisões, já que esse tipo de participação conferiria ao cidadão um grau maior de controle sobre sua vida e sobre o entorno em que vive, além de permitir que as decisões coletivas sejam aceitas mais facilmente pelo indivíduo. Importante destacar que, nessa abordagem, as instituições participativas não ameaçariam a liberdade porque seu próprio funcionamento (participativo) garante a liberdade.

\footnotetext{
${ }^{2}$ Segundo a autora, o aspecto pedagógico da participação não estaria ligado exclusivamente às implicações sobre o comportamento individual, mas também às instituições.
} 
Essas contribuições clássicas apontadas em Pateman (1992) sugerem que a ação política e social responsável depende em larga medida do tipo de instituições no interior das quais os indivíduos têm de agir politicamente, e esse tipo de ação pública e responsável das instituições dependeria da participação, ou seja, o desenvolvimento do espírito público somente seria possível em instituições participativas.

Essa discussão remete, também, à importância dada ao desenho institucional em instituições participativas no que concerne, como visto acima, à capacidade dos consórcios em processarem institucionalmente estratégias e mecanismos de participação e de instrumentos de governança democrática. Como destacado pela literatura (LUNCHMANN, 2008; FUNG; WRIGHT, 2003), o desenho institucional constitui um fator de grande importância, no que se refere às características que podem favorecer ou arrefecer a qualidade dos processos deliberativos e participativos.

Como destacado em Fung $(2004,2006)$, as modificações do desenho institucional podem trazer muitas possibilidades para o aprofundamento democrático, associadas aos canais de participação institucionalizada. Em geral essas modificações no desenho institucional podem acontecer em três níveis: de quem participa, de como se comunicam e de como as decisões vinculam-se às políticas.

É importante lembrar, no que diz respeito ao primeiro nível, como faz Luchmann (2008), que a participação não é meramente o estabelecimento de um nível paritário; uma vez que a paridade pode não garantir a representação política, na presença de condições heterogêneas ou de desigualdades entre os participantes. Importante ressaltar ainda, quanto ao segundo nível, que se trata, como já apontado em Pateman (1992), da possibilidade de intervenção ou de influência nas tomadas de decisão, não estando, assim, associado a mecanismos de agregação de preferências, como o voto. O terceiro nível de variação institucional, que se refere basicamente ao grau de vinculação das decisões às políticas, sugere considerar o poder efetivo dos canais de participação na efetivação das políticas.

Essas considerações aportam elementos importantes para a análise de implementação de consórcios públicos no que diz respeito ao processamento institucional de canais de participação. Em primeiro lugar, sugerem que, como visto em Pateman (1992), a participação exige qualificação e mobilização para a ação, é um processo pedagógico; assim, formas institucionais de gestão compartilhada pressupõem também que os consórcios qualifiquem e mobilizem quem participa. Em segundo lugar, é preciso que o desenho institucional do consórcio defina a representatividade dos canais de participação, sobretudo porque canais de participação meramente consultivos têm pouca vinculação às decisões políticas. Em terceiro lugar, é necessário que os canais de participação institucionalizados 
ponderem as condições de heterogeneidade e de desigualdade presentes entre os participantes.

Além da participação, um outro elemento importante, também identificado nas experiências de consorciamento e que também mantém relação com a capacidade de gestão compartilhada, é a questão da definição do problema comum que, como dito, em tese, congregaria os municípios. Esse elemento está diretamente relacionado à política pública definida pelo consórcio.

Embora para alguns, como Bardach (1993), a definição do problema não seja a parte mais difícil da análise da política porque as dificuldades podem ser essencialmente manejáveis, seguramente não é uma definição objetiva, pois a conduta humana, a ação do governo, as oportunidades e prioridades são percebidas de maneiras diferentes, o que implica compreender que a definição dos problemas não é ausente de dificuldades e que os próprios problemas não são claros, mas são construídos à medida que nossa percepção sobre a realidade muda (SUBIRATS, 2006b).

Logo, a consideração quanto à tratabilidade dos problemas, como sugerem Sabatier e Mazmanian (2003), requer uma abordagem holística, sobretudo porque, muito dificilmente, é um único problema que se coloca como preocupação. Ademais, a definição do problema depende da subjetividade da construção do analista. Nesse aspecto, os problemas não estão lá fora, são construídos, definidos, classificados, explicados e avaliados (SUBIRATS, 2006b). Além disso, o enfoque dado ao problema público tem dado ênfase às maneiras como se resolvem os problemas, não enfatizando sobre que problemas chegam e como chegam a ser objeto de intervenção governamental através das políticas (NELSON, 1993).

Para que um problema seja considerado um "problema público", ou seja, para que esteja na agenda governamental, é preciso, de acordo com a abordagem clássica das políticas públicas, construí-lo e estruturá-lo (estabelecer a relação de causa e efeito), superando as armadilhas das polêmicas e controvérsias, possibilitando a construção de um consenso em torno dele, além disso, é preciso que o problema possibilite uma intervenção viável, ou seja, que seja compatível com as ferramentas, dispositivos e recursos disponíveis na estrutura governamental.

Logo, não há espaço na agenda pública e governamental para problemas mal definidos, formulados ou estruturados. Num certo sentido, a construção dos problemas públicos pressupõe também a construção de suas soluções (AGUILLAR Villanueva, 1992). Portanto, o entendimento de como se dá a construção do problema comum nos consórcios é fator importante para ponderar o grau de colaboração em torno da política promovida por esses arranjos. 
A seguir passamos ao estudo dos parâmetros para a análise política e institucional de consórcios públicos.

\section{Alguns parâmetros para a análise política e institucional de consórcios públicos intermunicipais}

Esses parâmetros tentam ajudar a responder algumas questões relevantes que dizem respeito aos consórcios, como, por exemplo: como as relações institucionais são sustentadas? Como o problema-comum é construído? Como são elaboradas as estratégias de gestão do arranjo? Elas estimulam a colaboração? O consórcio tem solidez financeira suficiente para conduzir suas ações? Como os atores participam da elaboração das ações e da tomada de decisões?

A seguir passaremos a considerar os parâmetros que julgamos pertinentes para a análise política e institucional dos consórcios públicos na produção compartilhada de políticas.

1. Densidade institucional: esse parâmetro pode contribuir para analisar a natureza das alianças construídas em torno dos consórcios, do ponto de vista das relações e dos papéis atribuídos aos atores envolvidos e da efetividade e autonomia institucional. A densidade institucional procura analisar as relações interinstitucionais, a fim de perceber as relações de poder emanadas entre o consórcio e os atores relevantes dos ambientes políticos, econômicos e sociais. Busca-se, por conseguinte, apreender o quanto a relação com outros atores influi na agenda das ações do consórcio e em sua sustentação institucional, bem como o modo dessa interação entre os atores coletivos e individuais (interesses comuns? espírito público? redução de custos de transação? valores? etc.). Assim, para informar a densidade institucional nos consórcios, entendemos ser preciso analisar:

1.1 A rticulação institucional: esse parâmetro objetiva identificar e analisar as relações interinstitucionais e saber se essas relações promovem trocas, se essas trocas são simétricas ou assimétricas, identificar os principais capitais trocados e se essas trocas induzem a algum de tipo de hierarquia em função dos capitais trocados (financiamento, apoio político etc.). Para tanto é importante identificar as articulações entre o consórcio e outros órgãos do poder público ou da iniciativa privada, importantes para a implementação das ações públicas objeto do consórcio. Esse critério objetiva, assim, identificar e compreender como são construídos os principais laços públicos, privados e socioculturais que estão articulados na promoção das intervenções do consórcio e quem são os atores relevantes, como, quando e em que condições participam institucionalmente dessas ações. 
1.2 A efetividade institucional: analisa a participação efetiva do consórcio nos municípios signatários, a partir do grau de cobertura das ações e projetos no conjunto dos municípios e da existência de uma burocracia específica que represente o consórcio no seu território de abrangência, bem como a dinâmica de relacionamento entre essas unidades burocráticas e entre estas e a burocracia municipal.

1.3 A autonomia institucional: analisa a capacidade institucional do consórcio de empreender e dar continuidade às suas ações, considerando sua aptidão política, técnica e administrativa desvinculada de outras instâncias de governo. Analisa também a capacidade de autonomia do consórcio diante da influência de ciclos político-eleitorais. Considera, portanto, a estabilidade do arranjo ao longo do tempo, a partir da identificação de aspectos que garantam sua continuidade, blindando-o de conjunturas desfavoráveis e constrangimentos que possam fazer soçobrar suas atribuições e sua capacidade de empreender ações públicas cooperadas. Assim, esse parâmetro pondera também, em última instância, a qualidade do pacto político estabelecido em torno do consórcio, entendendo que um pacto político consistente perdura ao longo do tempo, enquanto, ao contrário, um pacto político eventual, fundado meramente em oportunidades, denota uma existência frágil.

2. Trocas cognitivas: esse parâmetro dedica-se basicamente a compreender a construção e formulação do problema público elencado como comum pelo consórcio. Pretende-se, dessa forma, compreender como é construído o "problema público comum", que, teoricamente, induziria à cooperação por ato deliberado, de vontade, por parte dos municípios. Entende-se aqui a necessidade de identificar e entender as representações que se tornam referências para intervenção da política, identificar quem são e qual o papel dos atores interessados, bem como compreender como é "costurada" a concertação entre os atores, a partir de quais ideias ou quais representações. Como já ressaltado por Subirats (2006), o problema é uma construção analítica, não é a identificação de problemas que não nos satisfazem, também não é apenas a discrepância entre o que é e o que gostaríamos que fosse. É analítico porque precisa estar vinculado com a solução dele mesmo! Nesse sentido, esse parâmetro busca analisar o grau em que as trocas cognitivas, a partir de diferentes racionalidades, contribuem para construir o problema. Para tanto é importante compreender, ainda como sugerido por Subirats (2006b), como é colocado o problema, se se entende a situação colocada como um problema, por quem é colocado, se existem diferentes versões do problema e se há tensão e se sua intensidade é constante. 
Portanto, em síntese, esse parâmetro busca ponderar a contribuição cognitiva da diversidade institucional, política e cultural na proposição das questões-chave objeto de intervenção do consórcio. É, desse modo, uma maneira de analisar a diversidade cognitiva na formulação da agenda sobre a qual o consórcio irá agir. Esse parâmetro é construído basicamente a partir de quatro outras referências:

2.1 Identidade/Indução: esse parâmetro analisa em que medida se pode considerar que as identidades (econômica, territorial, cultural, geográfica, política etc.) aportam contribuição significativa na formulação dos problemas pelos atores que compõem o consórcio. Ou seja, o problema formulado é formatado por um tipo de identidade comum aos atores? Ou decorre de mecanismos institucionais de indução a uma agenda específica, em função de compromissos/interesses estabelecidos junto a agências, partidos, órgãos públicos, atores individuais etc.?

2.2 Intercâmbio: analisa em que medida pode-se considerar, na formulação do problema comum, a contribuição do intercâmbio de valores, símbolos, signos e demais representações na convergência de sentido às ideias propostas pelos atores relevantes.

2.3 Deslocamento: analisa em que medida a compreensão do problema é modificada em função das implicações políticas que o problema remete; dos condicionantes técnicos e financeiros, das mudanças socioeconômicas que afetam a percepção social sobre o problema, da complexidade e natureza da política que afeta o grau de consenso envolvido em torno da questão e da incerteza quanto ao entendimento efetivo da situação colocada como um problema.

3 Governança democrática: esse parâmetro tenta apreender em que medida a gestão do consórcio é feita a partir de um sentido de direção democrático que contemple a participação de outros atores e que, no seu exercício, esteja ligado à produção de regras, estratégias e mecanismos institucionais que estimulem a cooperação e/ou compensem a competição política, em vez de uma relação de mando e controle a partir da independência política e dos recursos materiais e econômicos que o staff executivo geralmente possui. Busca assim identificar as estratégias elaboradas pelo consórcio para manutenção dos vínculos das relações sinérgicas intergovernamentais, interorganizacionais e intramunicipais, apreendendo o que explica sua continuidade ao longo do tempo e os fatores que a arrefecem. Os parâmetros que informam esse parâmetro podem ser decompostos assim:

3.1 Coesão interna: esse parâmetro pode aferir a permanência da orientação da política à medida que há o convencimento de que os 
dispositivos institucionais em vigor são equânimes. Busca, portanto, analisar o grau de consensualidade produzido pelo consórcio, bem como identificar os mecanismos de promoção de ações concertadas. Para tanto, objetiva identificar os fatores, circunstâncias, valores e capitais fomentados pela gestão do consórcio que possam explicar a continuidade de relações sinérgicas intramunicipais na promoção das ações públicas empreendidas (custos de transação, espírito público, valores culturais, etc.).

3.2 Responsabilização: apreende a capacidade do consórcio em estabelecer relações sinérgicas intramunicipais, interorganizacionais e intergovernamentais com definições claras e com atribuições de responsabilidade específicas. Permite, também, verificar se as estratégias de cooperação empreendidas pelo consórcio não se traduzem em motivações contrárias com baixa definição na distribuição de responsabilidades, ensejando, de maneira contraproducente, baixa cooperação.

3.3 Capacidade resolutiva: esse parâmetro apreende a capacidade da gestão do consórcio em estabelecer mecanismos institucionais de gerenciamento de conflitos e também a habilidade em contornar disputas de grande envergadura; busca ainda identificar disputas que foram efetivamente resolvidas em função dos mecanismos estabelecidos pelos consórcios.

3.4 Interação social/Especialização: analisa em que medida a análise e proposição de alternativas para as ações públicas do consórcio, bem como as mudanças estruturais (técnicas/administrativas) produzidas são feitas a partir de interações sociais entre os mais distintos atores, ou se são estabelecidas a partir de grupos especializados, como agências técnicas.

4 Sustentabilidade financeira: esse parâmetro consiste na análise sobre a solidez dos mecanismos de sustentação financeira do consórcio, identificando as fontes de financiamento e receita para, então, analisar o grau de flexibilidade e autonomia econômico-financeira do consórcio ao longo do tempo. Esse parâmetro mostra-se extremamente relevante para demonstrar a capacidade do consórcio em empreender ações públicas de maneira endógena (a partir da contribuição dos cooperados) e para demonstrar a inserção desses arranjos nos fundos de financiamento público, a partir de projetos e programas específicos, o que reflete também a capacidade de articulação intergovernamental do consórcio. Além disso, o parâmetro é importante, sobretudo, porque, como os arranjos de cooperação consorcial são voluntários, o grau de autonomia 
financeira, precipuamente, no tocante à adimplência e regularidade das cotas de cada signatário, é útil para verificar o grau de enraizamento das relações de cooperação intramunicipal.

6 Participação e controle social: esse parâmetro apreende a capacidade dos consórcios em estabelecer canais institucionalizados de participação, aqui entendida na acepção proposta por Pateman (1992). Nesse sentido, o parâmetro analisa se esses arranjos contribuem, de fato, para ampliação de espaços democráticos de domínio público, bem como se são capazes de estabelecer relações de reciprocidade na promoção e formulação das ações públicas. Para tanto, entende-se aqui que o valor da participação e controle social não se circunscreve apenas às suas contribuições quanto a dar maior transparência e accountability e legitimidade às políticas públicas, mas inclui a capacidade que tem em melhorar a própria gestão pública, seja porque os programas podem ser mais bem adaptados às necessidades locais, favorecendo melhor uso dos recursos, seja porque a entrega dos serviços públicos pode ser de melhor qualidade, atendendo, portanto, melhor a demanda, seja porque pode mobilizar os recursos locais, pode melhorar a utilização e a manutenção das instalações e serviços governamentais ou mesmo porque pode incrementar as informações quanto às necessidade, prioridades e capacidades locais das comunidades, além de poder se constituir num mecanismo para atenuar as desigualdades e corrigir características de políticas marcadas por interesses de grupos de maior poder econômico. Ademais, como visto, a produção compartilhada de políticas públicas não se faz na ausência de participação social. Nesse sentido, a participação nos consórcios públicos deve possibilitar a gestão efetivamente cooperativa e amplamente democrática, facilitar o rompimento das relações hierárquicas de produção das políticas públicas, reduzir a lógica gerencialista da gestão pública, facilitar mudanças nas ações públicas monotemáticas empreendidas pelos consórcios e suscitar horizontalidades nessas ações. Assim, é importante que os acordos de concertação devam ser institucionalmente processados, com a participação dos atores tanto na elaboração como na tomada de decisões, não se restringindo a funcionarem como instâncias ratificadoras, mas também deliberadoras. Por outro lado, também é fundamental considerar que a participação não é um bem distribuído homogeneamente. Assim, é importante, também, ponderar o peso que a participação de certos grupos representa, pois com frequência há grupos com capacidade de representação desproporcional, influenciando diretamente na formação dos temas e alternativas propostos nesses arranjos. Portanto, para informar, minimamente, esse parâmetro, é preciso que a análise seja orientada a partir dos seguintes parâmetros: 
6.1 Mobilização: esse parâmetro está ligado ao que Pateman (1992) apontou como o caráter pedagógico da participação ligada às instituições no desenvolvimento do espírito público. Assim, esse parâmetro capta um aspecto importante do processo de participação, que é a capacidade dos consórcios em mobilizar os atores da sociedade civil à participação na formulação e implementação das ações públicas, bem como sua capacidade de incluir novos atores. A mobilização pode partir do processo de qualificação técnica e política dos atores para políticas específicas, como saúde, meio ambiente etc., mas pode, também, se configurar como criação de mecanismos participativos múltiplos, como a promoção de audiências, consultas populares, formações de conselhos consultivos etc.

6.2 Representatividade: capta o poder que os conselhos, fóruns ou outro canal de participação exerce sobre as ações públicas dos consórcios, a partir do nível de participação efetivamente exercido. Evidentemente a participação pode ser presidida sob diversos níveis: como canal de compartilhamento de informações, como meio de consulta, como forma de implementação etc. Logo, a representatividade da participação dependerá do caráter institucional desenhado e promovido pelo consórcio; portanto, a participação poderá ter um caráter consultivo, regulatório, alocativo ou deliberatório.

6.3 Intersetorialidade: analisa em que medida os canais de participação do consórcio promovem algum tipo de articulação horizontal com outros canais de participação da sociedade civil em outras políticas e programas. Essa perspectiva contribui para a redução da verticalização e excessiva setorialização das ações públicas.

6.4 Heterogeneidade/Desigualdade: esse parâmetro objetiva localizar os principais constrangimentos que podem obstar a participação efetiva dos atores da sociedade civil junto ao consórcio, no tocante às diferenciações entre os atores. Portanto, analisa o grau de assimetrias que existem quanto ao conhecimento, informação e competência especializada que podem produzir desigualdades na participação, bem como a capacidade de certos atores em mobilizar recursos, interesses e agendas de maneira desproporcional aos demais, contribuindo para uma participação com elevado grau de heterogeneidade.

6.5 Fiscalização: esse parâmetro identifica quais os canais de controle existentes nos consórcios públicos; se existem apenas os de natureza externa, exigidos pelo regramento legal, ou se há fóruns ou comitês de controle interno. Analisa, ainda, sob quais aspectos efetivamente há 
controle: quanto à probidade do recurso público, quanto à transparência da gestão, quanto à estruturação democrática do processo de formulação, quanto ao resultado efetivo das ações etc.

Os parâmetros elencados aqui não constituem critérios hierárquicos e/ou mutuamente exclusivos que possam determinar o sucesso ou insucesso das ações consorciadas. Funcionam como "janelas temáticas" através das quais podemos aprofundar a análise sobre os consórcios públicos sob determinados aspectos. Assim, ressaltam questões que precisam ser consideradas na análise dos consócios enquanto espaços de produção compartilhada de políticas.

Evidentemente, embora não tenham uma hierarquia ou uma sequência rígida que conectam implicações, os parâmetros mantêm uma relação horizontal e dialogam entre si, sendo, inclusive, complementares.

Se considerarmos, por exemplo, a análise da densidade institucional, podemos compreender que a natureza da articulação institucional pode afetar a forma como se dá a construção do problema, podendo deslocar as identidades e induzir agendas específicas, fragilizando, assim, o potencial das trocas cognitivas na formulação do problema-comum.

Assim, se admitirmos que a construção do problema-comum parte de uma indução, dada a natureza da articulação institucional construída, que pode impor certas hierarquias, isso pode afetar também a governança do consórcio, seja porque é possível que haja baixa coesão em torno da agenda específica induzida (supondo baixa consensualidade) ou porque a capacidade de gerar responsabilização pode ser obstruída em função da dificuldade de estabelecer efetivamente atribuições específicas junto aos municípios signatários.

Nesse contexto, é muito provável que as estratégias de governança acabem por produzir baixa interação social e alto grau de especialização na proposição de alternativas e ações. O que, por outro lado, pode afetar sensivelmente a participação efetiva dos demais atores, implicando, ainda, no nível de representatividade dos atores.

\section{Considerações finais}

A proposta deste artigo foi a de apresentar parâmetros mínimos para análise política e institucional dos consórcios públicos, enquanto espaços de produção compartilhada de políticas. Para tanto, partiu-se, inicialmente, da análise de algumas evidências dos principais gargalos das experiências de consorciamento nacionais e internacionais. 
As análises puderam indicar que muitos dos problemas estão relacionados com a baixa institucionalidade desses arranjos, com a imprecisão do que são, de fato, problemas comuns e com a dificuldade de estruturação de mecanismos participativos e democráticos. Evidentemente isso passa, também, pela construção política desses consórcios, pelos interesses estratégicos envolvidos, pelos obstáculos legais e institucionais na implementação das políticas, o que resvala, ainda, no desenho institucional desses arranjos.

Em seguida considerou-se, sucintamente, elementos fundamentais para uma estratégia de gestão compartilhada de política, no tocante à participação e à construção do problema comum. Assim, partindo das análises de evidências empíricas e de elementos teóricos, pôde-se propor, de maneira razoável, alguns critérios de análise que problematizam as experiências de consorciamento.

Para facilitar essa compreensão, propusemos, então, parâmetros que ajudam a responder algumas questões seminais, por exemplo: como as relações institucionais são sustentadas? Como o problema-comum é construído? Como são elaboradas as estratégias de gestão do arranjo? Elas estimulam a colaboração? O consórcio tem solidez financeira suficiente para conduzir suas ações? Como os atores participam da elaboração das ações e da tomada de decisões?

É nesse sentido que o artigo tenta contribuir para essa discussão, ao colaborar, portanto, na compreensão e no aprendizado quanto às limitações, constrangimentos e potencialidades que esses arranjos podem implicar, e isso passa, necessariamente, pelo desenho institucional da política e do arranjo, pelas condições políticas e, fundamentalmente, pelo elemento de coesão, da identidade que congemina a mobilização dos atores em uma ação coletiva.

\section{Referências bibliográficas}

ABRUCIO, Fernando L.; SANO, Hironobu; SYDOW, Cristina T. Radiografia do associativismo territorial brasileiro: tendências, desafios e impactos sobre as regiões metropolitanas. In: KLINK, Jeroen. (Org.). Governança das metrópoles: conceitos, experiências e perspectivas. São Paulo: Annablume, 2010. p. 21-48.

Aguilar Villanueva, L. F. El estudio de las políticas publicas. Antologías I. México: Miguel Ángel Porrúa, 1992.

BARDACH, Eugene. Problemas en la definición de problemas en el análisis de políticas. In: Aguilar VilLANUEVA, Luis F. (Ed.). Problemas públicos y agenda de gobierno. México: Porrúa, 1993. p. 219-233.

BRITO, A. S. Consórcios intermunicipais e produção de políticas públicas: o Consórcio Intermunicipal de Produção e Abastecimento de São Luís - MA (CINPRA - MA) e proposta para análise de implementação de consórcios públicos. Rio de Janeiro: UFRRJ/CPDA, 2017 (tese de doutorado). 
CACERES, Pamela del Valle. La articulación política en los procesos asociativos intermunicipales: alcances y limitaciones. In: CONGRESSO INTERNACIONAL DEL CLAD SObRe Reforma del ESTAdo y de LA AdMINISTRACIón PúblicA, 10., Santiago, Chile, 2005. Anais... Satiago: Clad, 2005.

CASTEllano, M. Relações entre o poder público e a sociedade na gestão dos recursos hídricos: o caso do Consórcio Intermunicipal das Bacias Hidrográficas dos Rios Piracicaba, Capivari e Jundiaí, 2007 PROCAM - Departamento de Ciências Ambientais, USP, 2007 (tese de doutorado).

Choconi, Silvia Alicia. El caso de los consórcios productivos en la Provincia de Buenos Aires - Argentina. Problemas de Desarrollo. Revista Latino Americana de Economia, v. 34, n. 135, 2006.

COLLANTES, Juan Cruz Alberdi. La cooperacion municipal en el Bidasoa: de la accion local al consorcio internacional. Investigación y espacio, Espanha, Lurralde, n. 29, p. 87-113, 2006.

Cravacuore, Daniel Alberto. La gestión de consórcios intermunicipales en la província de Buenos Aires: análisis de caso. In: CONGRESSO INTERNACIONAL DEL CLAD SOBRe LA Reforma del ESTAdo y de LA AdMinsitración PúBliCA, 5., Santo Domingo, Rep. Dominicana, 2000. Anais... Santo Domingo: Clad, 2000. p. 1-12.

CRUz, M. C. M. T. Consórcios intermunicipais de saúde, educação e assistência social no Estado de São Paulo. In.: Informativo CEPAM. Consórcio: uma forma de cooperação intermunicipal. São Paulo: Fundação Prefeito Faria Lima - Cepam. Unidade de Políticas Públicas - UPP, v.1, n.2, 2001.

CRUz, M. C. M. T et al. Consórcios intermunicipais de desenvolvimento: mudando para sobreviver. Fundação Prefeito Faria Lima - CEPAM, São Paulo, 2005a. Disponível em: <www.cepam.sp.gov.br/arquivos/artigos/5_Consorcio_site.pdf>. Acesso em: 04 abr. 2009.

Cooperação intermunicipal: a experiência do estado de São Paulo, Brasil. In: CONGRESSO INTERNACIONAL DEL CLAD SOBRE LA REFORMA DEL ESTADO Y DE LA AdMINISTRACIÓN PÚBliCA, 10., Santiago, Chile, 2005b. p. 18 -21. Disponível em:

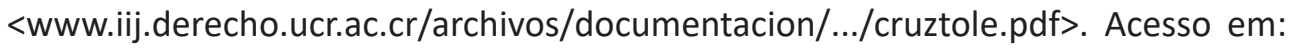
04 abr. 2009.

Dagnino, Evelina; Olvera, Alberto J.; PAnfichI, Aldo. Para uma outra leitura da disputa pela construção democrática na América Latina. In.: DAGNINO, Evelina, OlverA, Alberto J.; PANFICHI, Aldo (Orgs.). A disputa pela construção democrática na America Latina. São Paulo: Paz \& Terra; Campinas: Unicamp, 2006.

DALLABRIDA, Valdir Roque; ZIMERMANN, Viro José. Descentralização na gestão pública e estruturas subnacionais de gestão do desenvolvimento: o papel dos consórcios intermunicipais. Revista brasileira de Gestão e desenvolvimento Regional, v. 5, n. 3, 2009.

FUNG, A. Receitas para esferas públicas: oito desenhos institucionais e suas consequências. In: Coelho, V. S. R.; NoBre, M. (Orgs.). Participação e deliberação: teoria democrática e experiências no Brasil contemporâneo. São Paulo: 2004. 
. Varieties of participation in complex governance. Public Administration Review, Washington (DC), v. 66, special issue s1, p. 66-75, 2006.

GUIMARÃES, Luísa; GOMES, Maria Angélica. Contexto institucional e regulatório do desenvolvimento de quatro experiências de consórcios de saúde. In: INFORMATIVO CEPAM. Consórcio: uma forma de cooperação intermunicipal. São Paulo: Fundação Prefeito Faria Lima - Cepam. Unidade de Políticas Públicas - UPP, v.1, n.2, 2001.

Gutierrez, Fermin Rodríguez; Fernandez, Rafael Menendez; Nevado, Adrian Cadenas. Comarcas, Consorcios y otras experiências innovadoras de cooperación territorial en España. In: Fundear. Innovaciones em Política Territorial: Comarcas y otras experiências internacionales de cooperación intermunicipal. Fundación Economía Aragone - Fundear, Zaragoza, 2007.

HULST, R.; MONTFORT, A. Inter-municipal cooperation in Europe. Springer, 2007.

JOUVE, Bernard; LEFEVRE, Christian. La organización del gobierno en areas

metropolitanas europeas. In: Fundear. Innovaciones em política territorial: comarcas y otras experiências internacionales de cooperación intermunicipal. Fundación Economía Aragone - Fundear. Espanha: Zaragoza, 2007. p. 121-128.

KEINERT, Tania Margarete Mezzomo; RosA, Tereza Etsuko da Costa. Descentralização e parceria estado-município: o consórcio como instrumento da política estadual de saúde. In: Informativo CEPAM. Consórcio: uma forma de cooperação intermunicipal. São Paulo: Fundação Prefeito Faria Lima - Cepam. Unidade de Políticas Públicas UPP, v.1, n.2, 2001.

LAHÓz, Francisco Carlos Castro; BROCHI, Daltro Favero. O consórcio intermunicipal das bacias dos rios Piracicaba e Capivari e a gestão compartilhada dos recursos hídricos. In.: Informativo CEPAM. Consórcio: uma forma de cooperação intermunicipal. São Paulo: Fundação Prefeito Faria Lima - Cepam. Unidade de Políticas Públicas - UPP, v.1, n.2, 2001.

LACZYNSKI, Patrícia; ABRUcio, Fernando, L. Desigualdade e cooperação federativa: um novo olhar para a discussão dos consórcios. In: TREVAS, Vicente; CHERUBINE, Marcela (Org.). Consórcios públicos e as agendas do Estado brasileiro. São Paulo: Fundação Perseu Abramo, 2013.

LÜCHMANN, L. H. H. O desenho institucional dos conselhos gestores. In: LYRA, R. P. (Org.). Participação, democracia e segurança pública. A experiência brasileira. João Pessoa: UFPB, 2008.

MANTOVANI, Mario César. Consórcio intermunicipal: instrumento de ação e desenvolvimento de políticas públicas e participação social em meio ambiente. In: INFORMATIVO CEPAM. Consórcio: uma forma de cooperação intermunicipal. São Paulo: Fundação Prefeito Faria Lima - Cepam. Unidade de Políticas Públicas - UPP, v.1, n.2, 2001.

Melo, Vanessa Paternostro et al. Consórcio intermunicipal do Vale do Jiguiriçá. Bahia: uma análise sob a ótica das configurações em rede. In.: ENCONTRO DE ESTUDOS ORGANIZACIONAIS, 2002. Anais... Recife: Observatório da realidade organizacional: PROPAD/UFPE, ANPAD, 2002, 1 Cd. 
NELSON, B. La formación de una agenda: el caso del maltrato a los niños. In: AgUILAR Villanueva, L. F. (Ed.) Problemas públicos y agenda de gobierno. México: Miguel Ángel Porrúa, 1993. p.105-140.

Olson, Mancur. A lógica da Açao Coletiva: os benefícios públicos e uma teoria dos grupos sociais. São Paulo: Edusp, 1999.

Mancur. The rise and decline of nations: economic growth, stagflation and social rigidities. New Haven: Yale University Press, 1982.

Pateman, Carole. Participação e Teoria Democrática. Rio de Janeiro: Paz e Terra, 1992.

SANTOS, Boaventura de Sousa; AVRITZER, Leonardo. Introdução: para ampliar o cânone democrático. In: SANTOS, Boaventura de Sousa. Democratizar a democracia: os caminhos da democracia participativa. Rio de Janeiro: Civilização Brasileira, 2002.

STOKER, Robert P. Un marco de análisis para el régimen de implementación: cooperación y reconciliación entre los imperativos federalistas. In: AGUILAR VILLANUeVA, L. F. Colección de el estudio de las políticas públicas. México: Editorial Porrúa, 2003.

SUBIRATS, Joan. Definición del problema. Relevancia pública y formación de la agenda de actuación de lós poderes públicos. In: SARAIVA, Enrique; Ferrarezı, Elisabete. Políticas Públicas. Brasília: Enap, 2006a. 317p.

SUBIRATS, Joan. El papel de la burocracia en el processo de determinações e implementación de las políticas públicas. In: SARAIVA, Enrique; FerRAREZI, Elisabete. Políticas Públicas. v. 2. Brasília: Enap, 2006b, 317p.

TeIXEIRA, Marco Antonio C. Democratização do espaço público: a experiência do Consórcio Quiriri. In: CONGRESSO INTERNACIONAL DEL CLAD SOBRE LA REFORMA DEL EstAdo y DE LA AdMINISTRACIÓn PÚBliCA, 9., Madrid, España, 2004. Anais... Madrid: Clad, 2004. p. 2-5.

TREVAS, Vicente Y Plá. A lei dos consórcios públicos como um novo instrumento de fortalecimento da federação brasileira. 2007. Disponível em <http://www.franca. unesp.br/cadir>. Acesso em: 23 maio 2008.

\section{Alexsandro Sousa Brito}

Possui doutorado em Ciências Sociais, na área de Desenvolvimento, Agricultura e Sociedade, pela universidade Federal Rural do Rio de Janeiro (UFRRJ). Atualmente é Professor Adjunto do Departamento de Economia da Universidade Federal do Maranhão (UFMA).

Contato: alex_brito@yahoo.com 